\title{
THE IMPACT OF TYPHOONS ON ECONOMIC ACTIVITY IN THE PHILIPPINES: EVIDENCE FROM NIGHTLIGHT INTENSITY
}

Eric Strobl

\section{NO. 589}

July 2019

\section{ADB ECONOMICS WORKING PAPER SERIES}


ADB Economics Working Paper Series

\section{The Impact of Typhoons on Economic Activity in the Philippines: Evidence from Nightlight Intensity}

Eric Strobl

No. 589 | July 2019
Eric Strobl (eastrobl13@gmail.com) is a professor in the Department of Economics and Oeschger Centre for Climate Change Research, University of Bern.

This paper was prepared as background material for the Asian Development Outlook 2019 theme chapter on

"Strengthening Disaster Resilience." 
(C) 2019 Asian Development Bank 6 ADB Avenue, Mandaluyong City, 1550 Metro Manila, Philippines

Tel +632632 4444; Fax +6326362444

www.adb.org

Some rights reserved. Published in 2019.

ISSN 2313-6537 (print), 2313-6545 (electronic)

Publication Stock No. WPS190278-2

DOI: http://dx.doi.org/10.22617/WPS190278-2

The views expressed in this publication are those of the authors and do not necessarily reflect the views and policies of the Asian Development Bank (ADB) or its Board of Governors or the governments they represent.

ADB does not guarantee the accuracy of the data included in this publication and accepts no responsibility for any consequence of their use. The mention of specific companies or products of manufacturers does not imply that they are endorsed or recommended by ADB in preference to others of a similar nature that are not mentioned.

By making any designation of or reference to a particular territory or geographic area, or by using the term "country" in this document, $A D B$ does not intend to make any judgments as to the legal or other status of any territory or area.

This work is available under the Creative Commons Attribution 3.0 IGO license (CC BY 3.0 IGO)

https://creativecommons.org/licenses/by/3.o/igo/. By using the content of this publication, you agree to be bound by the terms of this license. For attribution, translations, adaptations, and permissions, please read the provisions and terms of use at https://www.adb.org/terms-use\#openaccess.

This CC license does not apply to non-ADB copyright materials in this publication. If the material is attributed to another source, please contact the copyright owner or publisher of that source for permission to reproduce it. $\mathrm{ADB}$ cannot be held liable for any claims that arise as a result of your use of the material.

Please contact pubsmarketing@adb.org if you have questions or comments with respect to content, or if you wish to obtain copyright permission for your intended use that does not fall within these terms, or for permission to use the ADB logo.

Corrigenda to ADB publications may be found at http://www.adb.org/publications/corrigenda.

Note:

ADB recognizes "China” as the People’s Republic of China and "Hong Kong” as Hong Kong, China.

The ADB Economics Working Paper Series presents data, information, and/or findings from ongoing research and studies to encourage exchange of ideas and to elicit comment and feedback about development issues in Asia and the Pacific. Since papers in this series are intended for quick and easy dissemination, the content may or may not be fully edited and may later be modified for final publication. 


\section{CONTENTS}

TABLES AND FIGURES

ABSTRACT

ABBREVIATIONS

$\begin{array}{lll}\text { I. INTRODUCTION } & 1\end{array}$

II. DATA AND METHODOLOGY 2

A. Nightlights 2

B. Grid Cell Level Typhoon Damages 4

C. Summary Statistics 9

III. ECONOMETRIC ANALYSIS

A. Regression Framework 10

B. Econometric Results 10

IV. RISK ANALYSIS $\quad 12$

A. $\quad$ Extreme Value Analysis $\quad 12$

B. Threshold Selection $\quad 12$

C. Results 12

$\begin{array}{lll}\text { V. CONCLUSIONS } & 17\end{array}$

$\begin{array}{ll}\text { REFERENCES } & 19\end{array}$ 


\section{TABLES AND FIGURES}

\section{TABLES}

$1 \quad$ Summary Statistics

2 Regression Results

10

3 Impact Return Periods by Region

\section{FIGURES}

$1 \quad$ Nightlight Intensity, 2013

2 Total Gross Domestic Product and Total Nightlight Intensity, 1992-2013 4

3 Total Gross Domestic Product and Total Nightlight Intensity-Autonomous Muslim Mindanao, Cordillera, National Capital Region, and Region I 5

4 Total Gross Domestic Product and Total Nightlight Intensity-Regions II, III, IV, and IX 5

5 Total Gross Domestic Product and Total Nightlight Intensity-Regions V, VI, VII, and VIII 6

6 Total Gross Domestic Product and Total Nightlight Intensity-Regions X, XI, XII, and XIII 6

$7 \quad$ Tropical Storms, 1987-2013 8

$8 \quad$ Histogram of Tropical Storms, 1987-2013 11

9 Mean Residual Life Plot: National Losses 13

10 Quantile-Quantile Plot: National Losses 14

$11 \quad \mathrm{~N}$-Year Return Period National Losses 15

12 Regions 16 


\begin{abstract}
We quantify the economic impact of typhoons in the Philippines. To this end we construct a panel data set of local economic activity derived from nightlight intensity satellite images and a cell level measure of typhoon damage constructed from storm track data, a wind field model, and a stylized damage function. Our econometric results reveal that there is a statistically and potentially economically significant, albeit short- lived, impact of typhoon destruction on local economic activity. Constructing risk profiles from a 60-year historical set of storms suggests that (near) future losses in economic activity for frequent (5-year return period) and rare (50-year return period) events are likely to range from between $1.0 \%$ and $2.5 \%$.
\end{abstract}

Keywords: economic impact, nightlights, Philippines, typhoons, wind field model

JEL codes: $017,044, \mathrm{Q} 54$ 
Typhoons are shown to have a significant negative, but short-lived impact on local economic activity, as proxied by the intensity of light usage at night. The historical distribution of typhoon storms in the past suggests that frequent storms are likely to cause damages of around 1\%, whereas rarer ones will reduce the local economy negatively up to nearly $3 \%$ when they strike.

\section{INTRODUCTION}

In all the world, the Philippines is one of the countries most prone to tropical storms, with on average about 6-9 typhoons making landfall per year since 1970 (Blanc and Strobl 2016). Some scientists predict that their intensity may increase with climate change (Knutson et al. 2010, Emanuel 2013). Moreover, regardless of any increase in intensity or frequency, their effects are likely to be exacerbated by the Philippines' rapidly growing population, particularly along the coast, and its localized environmental degradation (Holden and Marshall 2018). Unfortunately, the few existing studies on the impact of these storms in the Philippines have largely focused on specific aspects, rather than the economy as a whole. For example, Blanc and Strobl (2016) find that typhoons have caused losses in rice production of about 12.5 million tons since 2001, while Anttila-Hughes and Hsiang (2013) find that infant mortality rises by $13 \%$ after a typhoon. The purpose of this study is thus to quantify the economic impact of typhoons in the Philippines and to use these estimates to predict what expected (near future) impacts may be.

Importantly, much of the existing literature on the impact of tropical cyclones has tended to focus on national or regional effects and the results have been rather mixed.' However, while insightful, these macroeconomic studies are fairly limited in terms of providing useful information for formulating policies to build resilience. More specifically, tropical storms, as with most natural disasters, are inherently very local in nature and the local impact will likely be, at least to some extent, 'aggregated out' if researchers use too broad a regional unit of analysis. As a matter of fact, a number of papers investigate this "aggregation problem" to measure the impact of tropical storms, and found that aggregate data tend to underestimate the true impact of these extreme weather phenomena. For example, using yearly data Strobl (2011); Bertinelli and Strobl (2013); and Elliott, Strobl, and Sun (2015) show that national-level regressions can mask much of the impact of tropical storms at the local regional level.

The challenge for researchers wishing to do a convincing analysis of the impact of tropical storms is threefold. First, the economic unit of analysis needs to be observed before and after a storm event. Second, as noted above, it is important to model the impact of the storm locally, which means explicitly modeling the impact spatially to capture the fact that relatively small differences in distance can result in considerable differences in damage. To this end, there has been considerable progress in the economics literature as research has evolved from using simple event indicators or likely endogenous ex post measured damages to employing physical storm models to approximate the local impact (see, for example, Strobl 2012). The remaining, and perhaps greatest challenge, is being able to precisely quantify local economic activity to match it to the spatial heterogeneity of the storm impact. Data difficulty for most parts of the world have meant that most studies at best used fairly broad administrative regions. ${ }^{2}$

1 The early literature has tended to take a cross-country macroeconomic approach to examine the impact of a disaster on growth. Examples include Loayza et al. (2012); Strobl (2012); Ahlerup (2013); and Crespo Cuaresma, Hlouskova, and Obersteiner (2008). See Noy and duPont IV (2016) for a summary of the macroeconomic studies.

2 Broad administrative regions are used in, among others, Paxson and Rouse (2008); Leiter, Oberhofer, and Raschky (2009); Craioveanu and Terrell (2016); and Groen, Kutzbach, and Polivka (2017). For a map of the regions please see Figure 12. 
In this study, we follow the approach of Bertinelli and Strobl (2013); Elliott, Strobl, and Sun (2015); and Mohan and Strobl (2017) and use local nightlight intensity, as derived from satellite images, to investigate the impact of typhoons in the Philippines. Importantly, nightlights have recently found widespread use as a measure of local economic activity where other satisfactory proxies are not available; see, for instance, Harari and La Ferrara (2013), Hodler and Raschky (2014), and Michalopoulos and Papaioannou (2014). To construct the measure of local typhoon damages, we employ actual storm tracks within a wind field model and a stylized wind exposure based damage function. These two constructed data series provide us with a locally measured (approximately 1 square kilometer $\left[\mathrm{km}^{2}\right]$ ) balanced panel of over 120,000 economic units that are exposed to potentially damaging typhoon winds on average at least once every 3 years. Our econometric analysis shows that the effect of these storms can be substantial, but also that it is short lived. We then use historical storms dating back to 1950 and extreme value theory methods to construct risk profiles of damages nationally as well as regionally.

The remainder of the paper is organized as follows. In section II, we describe our data, the construction of our plant-level panel, and our baseline estimating equation. In section III, we present our econometric results. We conduct our risk analysis in section IV. Section V concludes.

\section{DATA AND METHODOLOGY}

\section{A. Nightlights}

The nightlight imagery we employ is provided by the Defense Meteorological Satellite Program satellites. In terms of coverage, each satellite has a 101 minute near-polar orbit at an altitude of about $800 \mathrm{~km}$ above the surface of the earth, providing global coverage twice per day, at the same local time each day, with a spatial resolution of about $1 \mathrm{~km}$ near the equator. The resulting images provide the percentage of nightlight occurrences for each pixel per year normalized across satellites to a scale ranging from 0 (no light) to 63 (maximum light). Yearly values were then created as simple averages across daily values of grids, and are available from 1992 to $2013 .{ }^{3}$ We use the stable, cloud-free series; see Elvidge et al. (1997). We depict the nightlight intensity in the Philippines in 2013 in Figure 1. Accordingly, as would be expected, much of the nighttime brightness is in and around the National Capital Region.

To assess how well nightlight intensity can proxy economic activity we depict the national gross domestic product (GDP) series (in millions of 2018 United States dollars, constant prices), taken from official figures published by the Philippines Statistics Authority, alongside the sum of total nightlight values for the period 1992-2013 in Figure 2. As can be seen, while the nightlight intensity appears to be more volatile, both series certainly seem to be moving together. We conducted a similar exercise for the main regions in the Philippines, where we grouped Region IV-A and Region IV-B into one region because for some of the earlier years, no separate GDP series were available. As can be seen from Figures 3, 4, 5, and 6, in most cases, they are relatively well correlated.

3 For the years when satellites were replaced, observations were available from both the new and old satellites. In this paper, we use the imagery from the most recent satellite but as part of our sensitivity analysis we also reestimated our results using an average of the two satellites and the older satellite only. The results of these latter two options were almost quantitatively and qualitatively identical. 
Figure 1: Nightlight Intensity, 2013

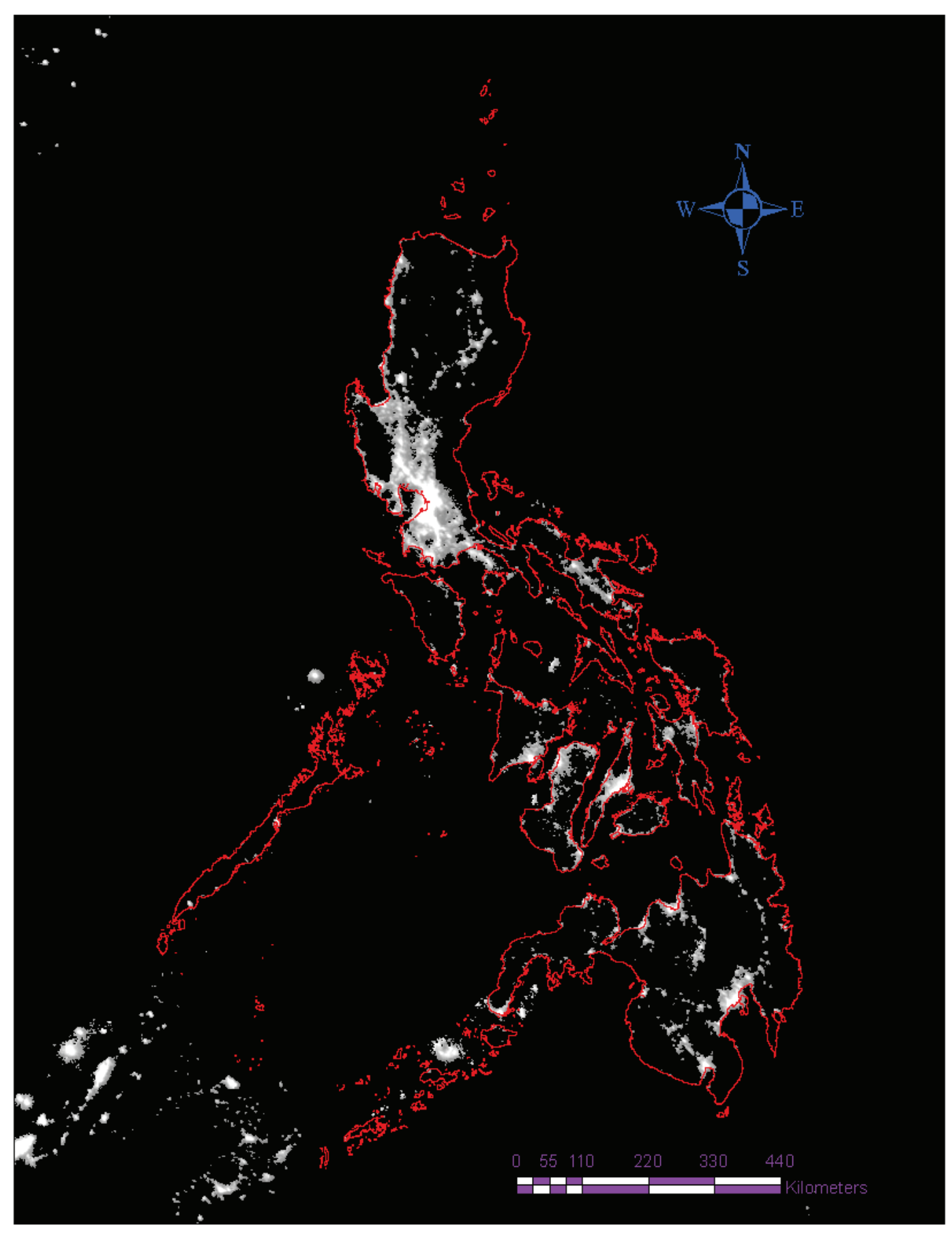

$\mathrm{E}=$ east, $\mathrm{N}=$ north, $\mathrm{S}=$ south, $\mathrm{W}=$ west.

Source: Authors' own data from Defense Meteorological Satellite Program satellites. 
Figure 2: Total Gross Domestic Product and Total Nightlight Intensity, 1992-2013

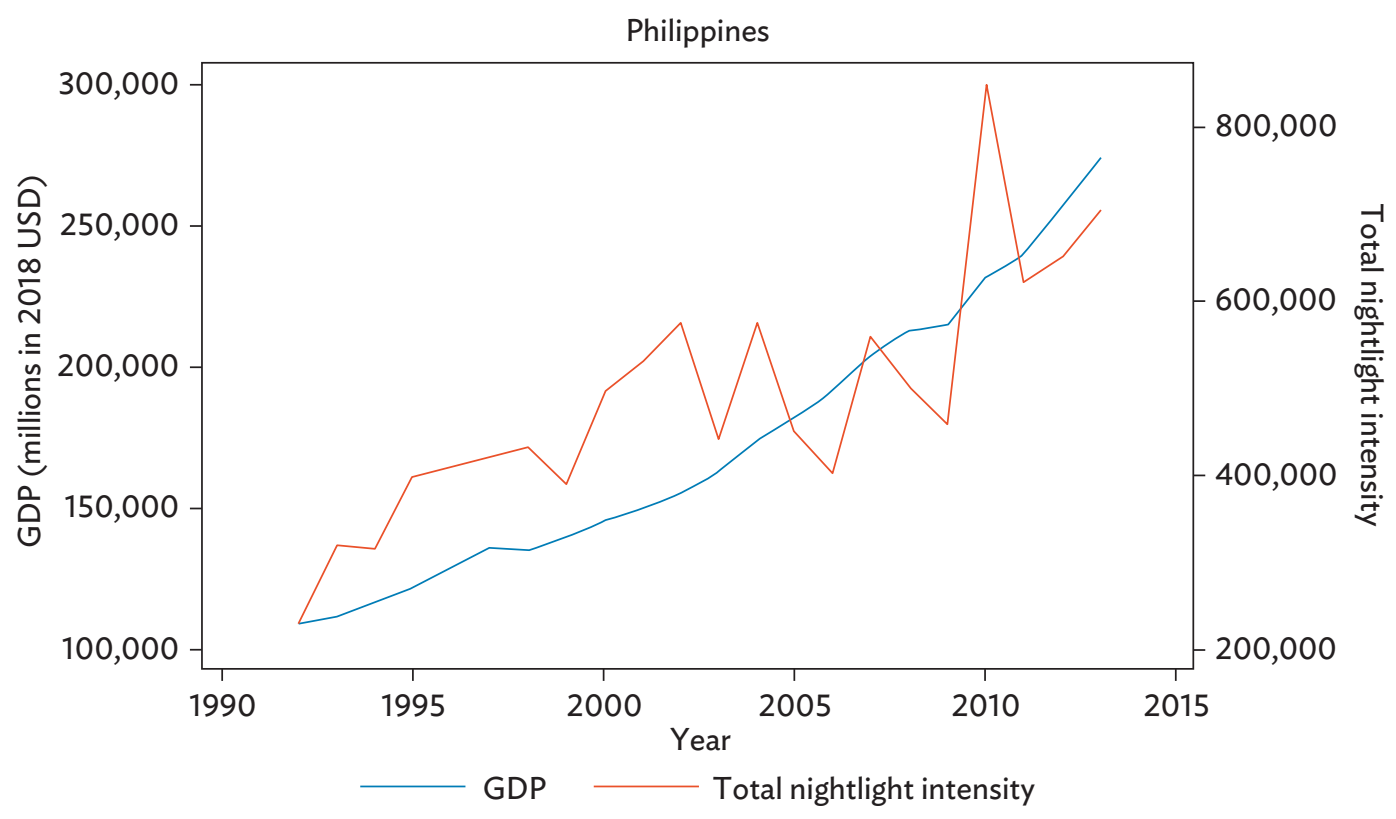

GDP = gross domestic product, USD = United States dollars.

Source: Author's own. GDP data were taken from the Philippine Statistics Authority (2015) and nightlight intensity data were from the Defense Meteorological Satellite Program (1992-2013), measured in normalized values on a 0-63 scale.

\section{B. Grid Cell Level Typhoon Damages}

The damage caused by a typhoon depends mainly on three related aspects: wind speed, flooding and/or excess rainfall, and storm surge. A simplifying and commonly adopted assumption in the literature is that the latter two effects, which are much more difficult to model, are highly correlated with wind speed and thus one can use wind speed as a proxy for the potential damage due to a typhoon strike. ${ }^{4}$ Here we also adopt this convention.

4 See Emanuel (2011) for a more detailed discussion on the relationship between wind speed and flooding and/or storm surge. 


\section{Figure 3: Total Gross Domestic Product and Total Nightlight Intensity- Autonomous Muslim Mindanao, Cordillera, National Capital Region, and Region I}
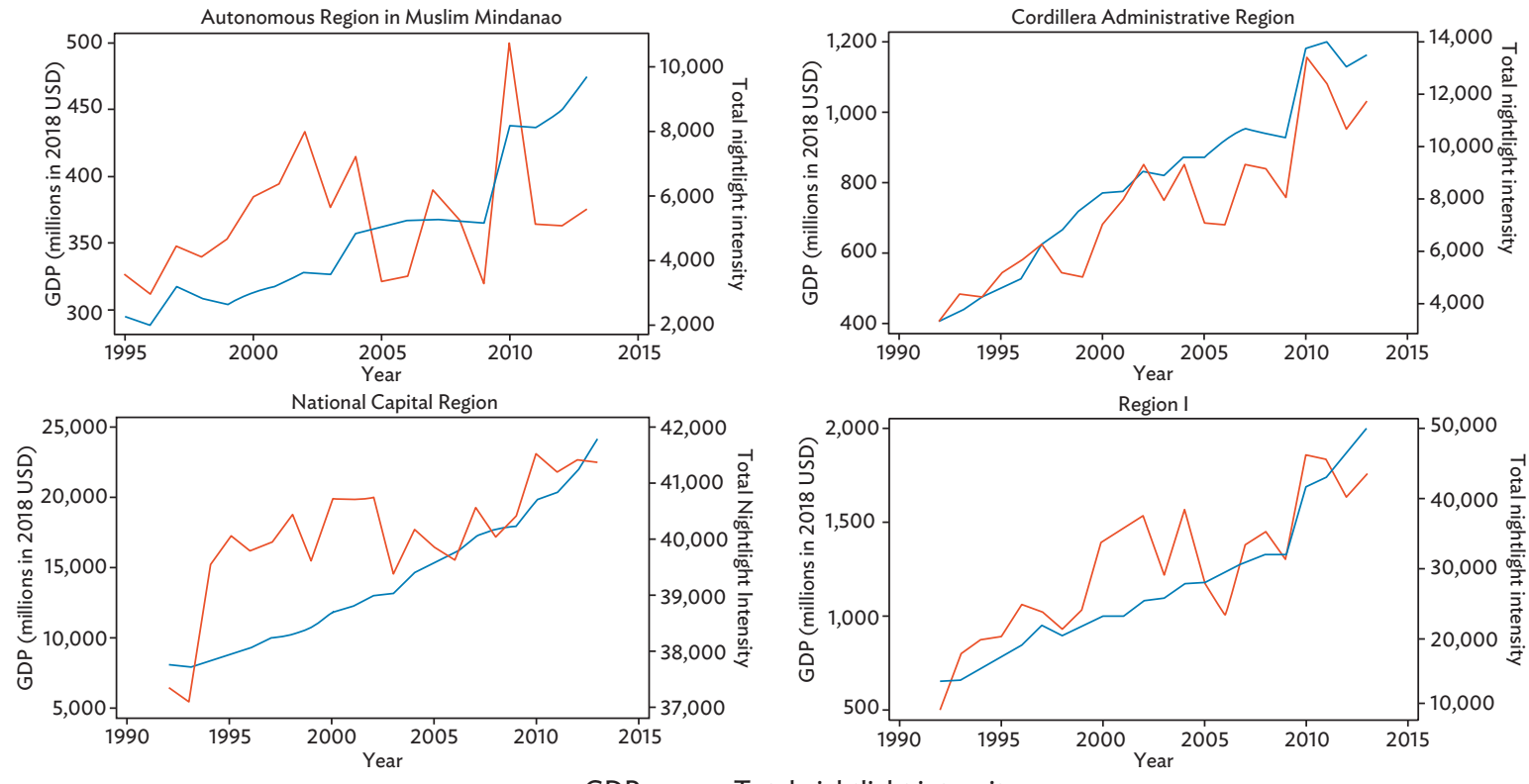

GDP = gross domestic product, $\mathrm{USD}=$ United States dollars

Note: Regions are defined in Figure 12.

Source: Author's own. GDP data were taken from the Philippine Statistics Authority (2015) and nightlight intensity data were from the Defense Meteorological Satellite Program (1992-2013), measured in normalized values on a 0-63 scale.

Figure 4: Total Gross Domestic Product and Total Nightlight Intensity-Regions II, III, IV, and IX
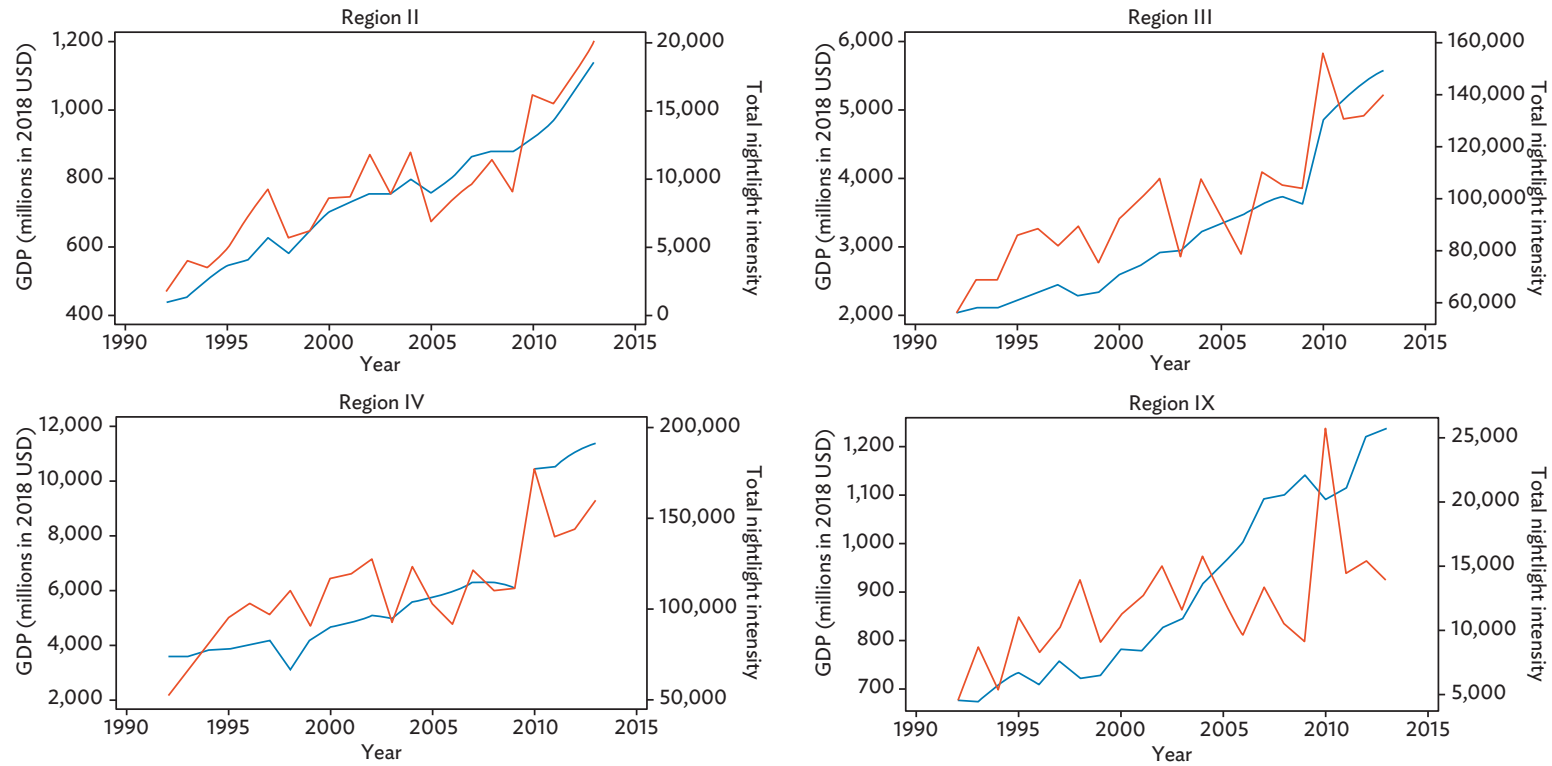

GDP Total nightlight intensity

GDP = gross domestic product, USD = United States dollars

Note: Regions are defined in Figure 12.

Source: Author's own. GDP data were taken from the Philippine Statistics Authority (2015) and nightlight intensity data were from the Defense Meteorological Satellite Program (1992-2013), measured in normalized values on a 0-63 scale. 
Figure 5: Total Gross Domestic Product and Total Nightlight Intensity-Regions V, VI, VII, and VIII
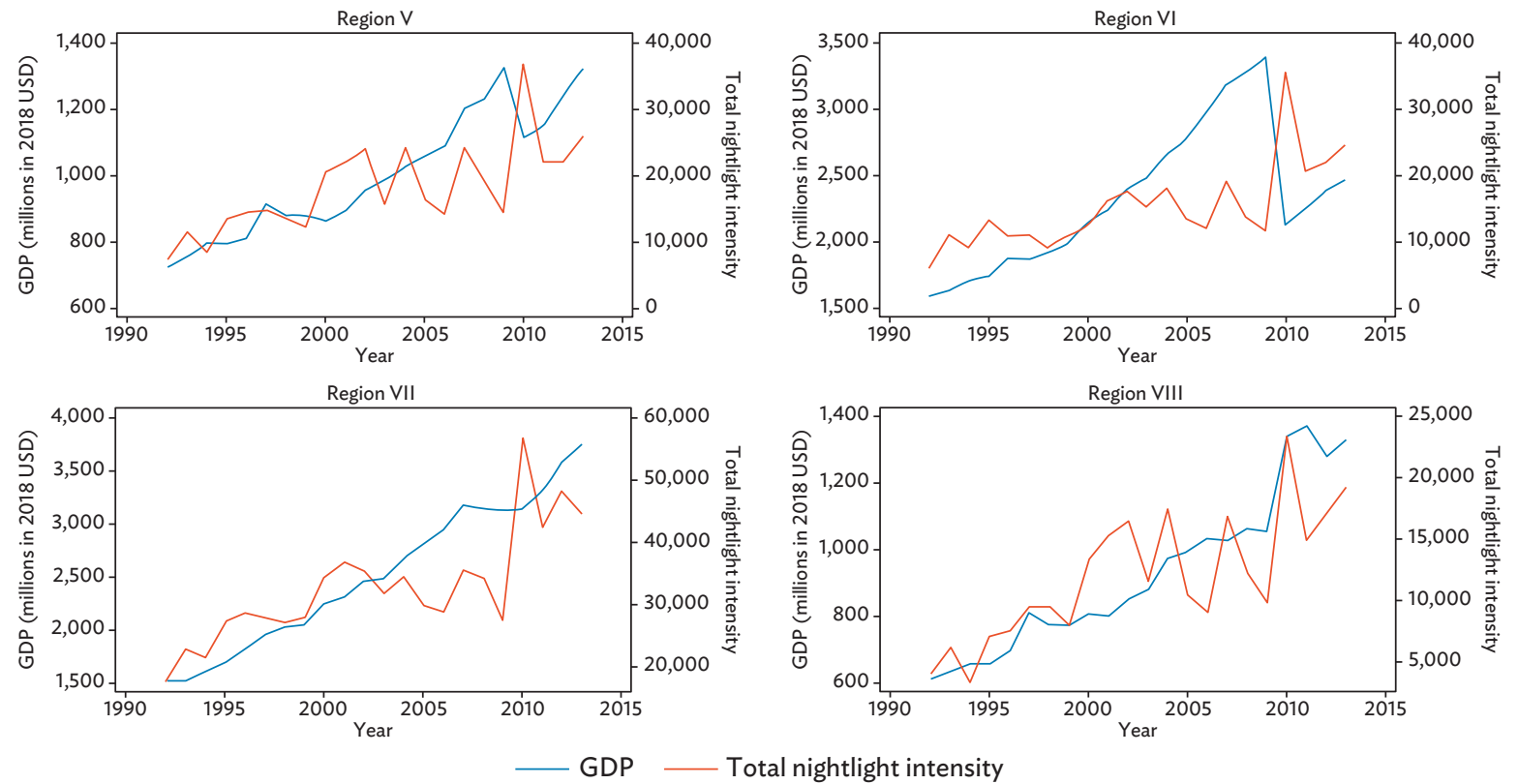

GDP = gross domestic product, USD = United States dollars

Note: Regions are defined in Figure 12.

Source: Author's own. GDP data were taken from the Philippine Statistics Authority (2015) and nightlight intensity data were from the Defense Meteorological Satellite Program (1992-2013), measured in normalized values on a 0-63 scale.

Figure 6: Total Gross Domestic Product and Total Nightlight Intensity-Regions X, XI, XII, and XIII
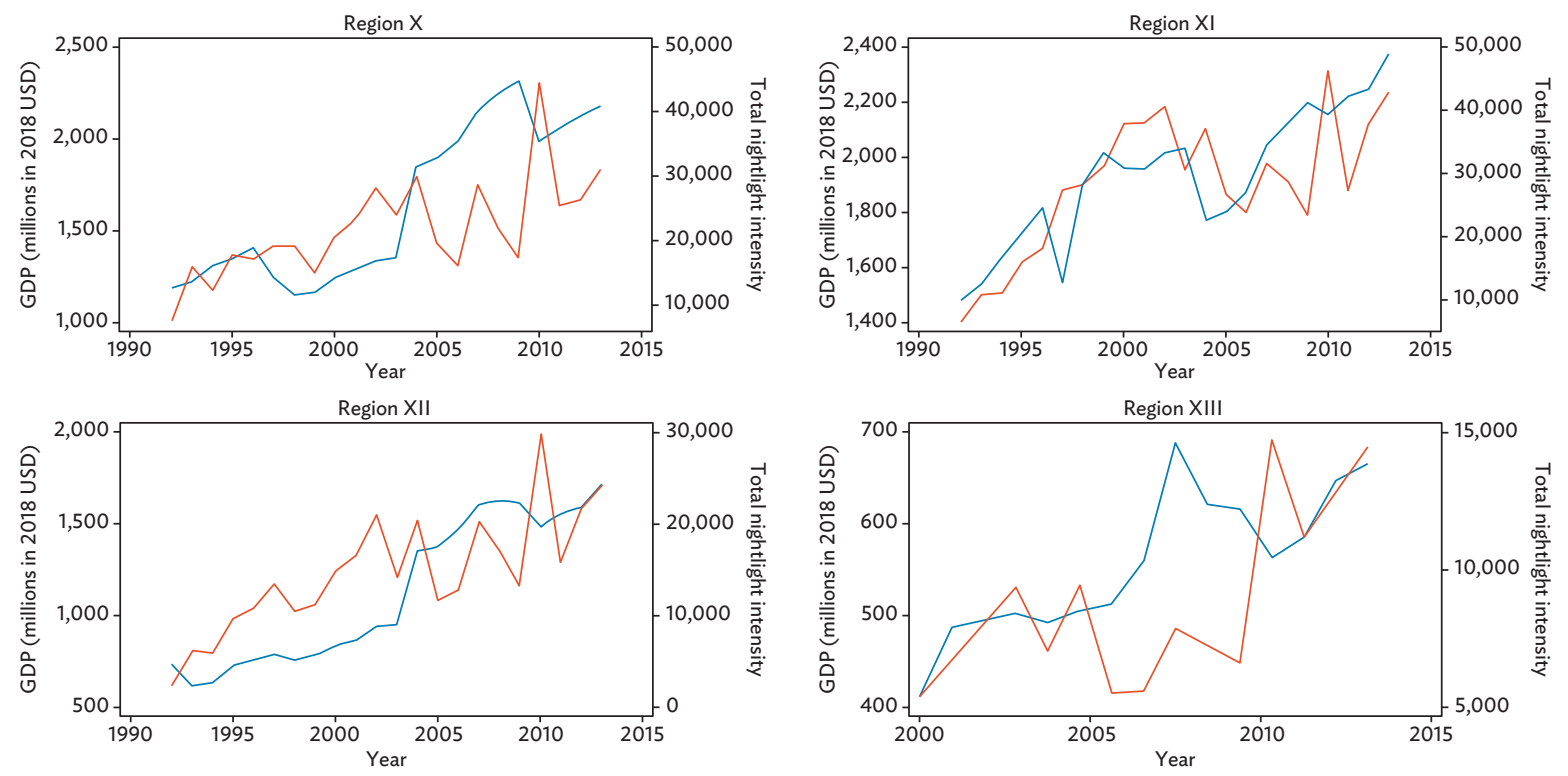

GDP

Total nightlight intensity

GDP = gross domestic product, USD = United States dollars.

Note: Regions are defined in Figure 12.

Source: Author's own. GDP data were taken from the Philippine Statistics Authority (2015) and nightlight intensity data were from the Defense Meteorological Satellite Program (1992-2013), measured in normalized values on a 0-63 scale. 


\section{Typhoon Tracks}

To model typhoon damage within the Philippines, we use storm tracks from the Best Track Archive for Climate Stewardship (IBTrACS) provided by the National Oceanic and Atmospheric Administration (Knapp et al. 2010). It is a unification of all best track data on tropical cyclones collected by weather agencies worldwide. Best track data are a postseason reanalysis from different available data sources, including satellites, ships, aviation, and surface measurements to describe the position and intensity of tropical cyclones. The unified data of the IBTrACS dataset identifies each storm uniquely by assigning an identification number, its geospatial position, and its intensity given by maximum sustained wind speed, among other characteristics. The data are reported at 6-hour intervals, and we linearly interpolated these to hourly data points. Figure 7 shows the tracks of typhoons and other tropical storms that formed around the Philippines between 1987 and 2013, where the red segment of the storm represents when it reached typhoon strength.

\section{Local Typhoon Wind Speed}

An important factor when it comes to measuring the damage to a locality is the wind speed that a location experiences during a typhoon and this will depend on the location relative to the movement and features of the storm. To model this, we apply the Boose, Serrano, and Foster (2004) version of the well-known Holland (1980) wind field model, according to which, the approximate local wind $k$, is given by:

$$
v_{i k t}=G F\left[V_{\max , k t}-S\left(1-\operatorname{SIN}\left(T_{i k t}\right)\right) \frac{V_{h, k t}}{2}\right]\left[\left(\frac{R_{\max , k, t}}{R_{i t}}\right)^{B_{k t}} \exp \left(1-\left[\frac{R_{\max , k, t}}{R_{i t}}\right] B_{k t}\right)\right]^{\frac{1}{2}}
$$

where $V_{\max }$ is the maximum sustained wind velocity anywhere in the typhoon, $T$ is the clockwise angle between the forward path of the typhoon and a radial line from the typhoon center to the point of interest $i, V_{h}$ is the forward velocity of the tropical storm, $R_{\max }$ is the radius of maximum winds, $R$ is the radial distance from the center of the tropical storm to point $i$, and $G$ is the gust factor. $F, S$, and $B$ are the scaling factors for surface friction, asymmetry due to the forward motion of the storm, and the shape of the wind profile curve, respectively.

In terms of implementing equation (1) the maximum wind speed $V_{\max }$ is taken from the IBTrACS dataset, $V_{h}$ can be calculated following the movement path of the storm, while $R$ and $T$ can be determined by using the relative position between the eye of the typhoon and our point of interest $i$. We set $G$ equal to 1.5 and $S$ equal to 1 following Paulsen and Schroeder (2005) and Boose, Serrano, and Foster (2004), respectively. For the surface friction indicator $F$, Vickery et al. (2009) suggest that in open water the reduction factor is around 0.7 and that there is a reduction in wind speed of around $14 \%$ on the coast and $28 \% 50 \mathrm{~km}$ inland.

Following Elliott, Strobl, and Sun (2015), we linearize the reduction factor to capture the friction effect of the typhoon as it moves inland. In terms of the pressure profile parameter $B$ and the radius maximum winds $R_{\max }$, we adopt Holland's (2008) approximation method and the parametric model of Xiao, Xiao, and Duan (2009). 
Figure 7: Tropical Storms, 1987-2013

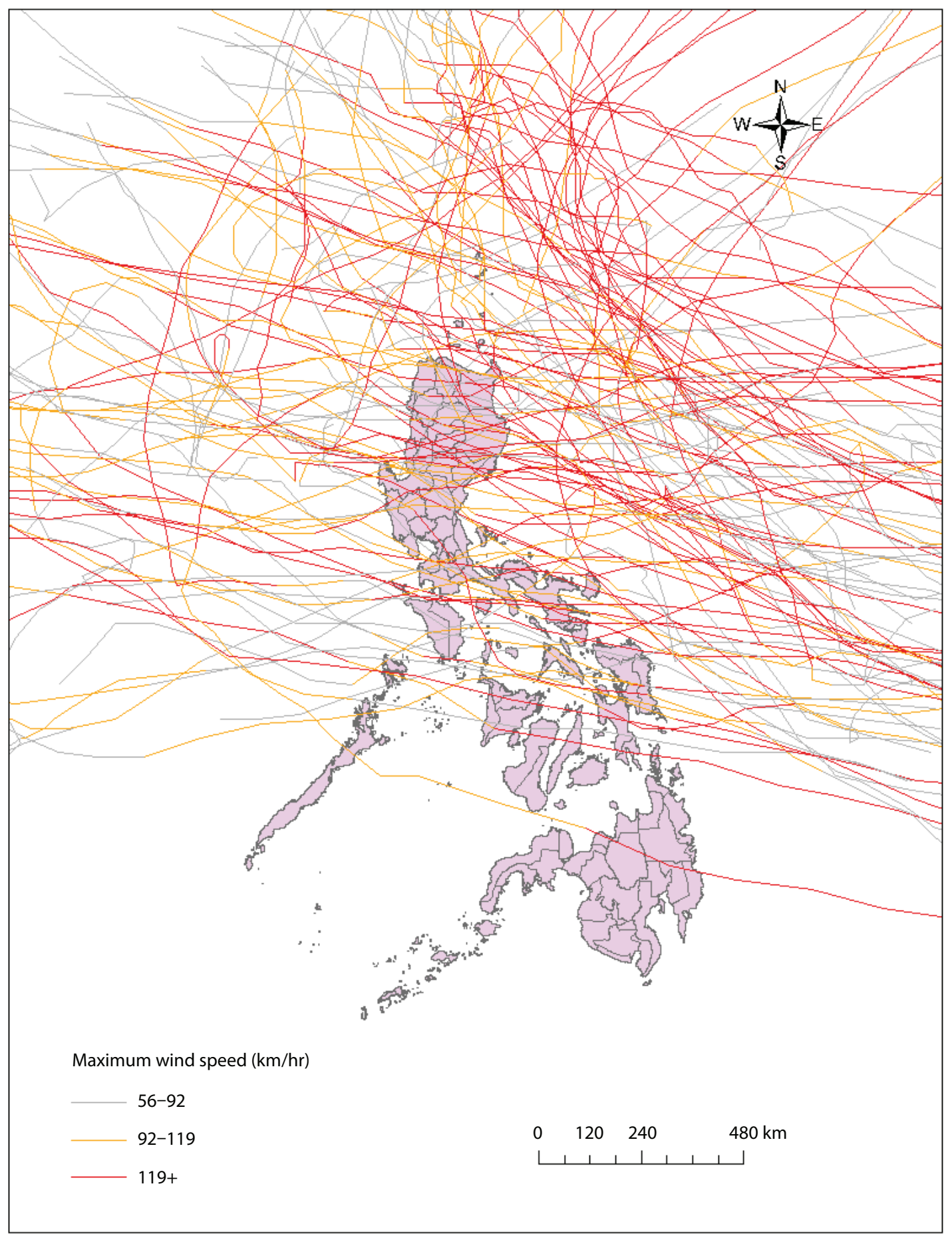

$\mathrm{E}=$ east, $\mathrm{hr}=$ hour, $\mathrm{km}=$ kilometer, $\mathrm{N}=$ north, $\mathrm{S}=$ south, $\mathrm{W}=$ west.

Source: Storm tracks are from Knapp, Kenneth. R., Michael C. Kruk, David H. Levinson, Howard J. Diamond, and Charles J. Neumann. 2010. "The International Best Track Archive for Climate Stewardship (IBTrACS) Unifying Tropical Cyclone Data." Bulletin of the American Meteorological Society 91 (3): 363-76. 


\section{Damage Function}

As noted by Emanuel (2011), there are energy dissipation reasons to assume that the relationship between wind speed experienced and damage incurred is to the cubic power. Moreover, there is unlikely to be any damage for winds that fall below $92 \mathrm{~km} /$ hour ( $\mathrm{hr}$ ). Incorporating these features and to ensure that the percentage of damage varies between 0 and 1, Emanuel (2011) proposes the following damage function for wind of storm $k$ experienced at location $i$ :

$$
f_{i k}=\frac{v_{i k}^{3}}{1+v_{i k}^{3}}
$$

where

$$
v_{i k}=\frac{M A X\left[\left(v_{i k}-v_{\text {thresh }}\right), 0\right]}{v_{\text {half }}-v_{\text {thresh }}}
$$

where $v_{i k}$ is the maximum wind speed of storm $k$ experienced at point of interest $i, v_{t h r e s h}$ is the threshold below which no damage occurs, and $v_{\text {half }}$ is the threshold at which half of the property is damaged. Following Emanuel (2011), we assume values of $92 \mathrm{~km} / \mathrm{hr}$ and $204 \mathrm{~km} / \mathrm{hr}$ for $v_{\text {thresh }}$ and $v_{\text {half, }}$, respectively.

Note that equation (1) is defined in terms of the percentage of damage caused per storm. Given that our nightlight data is annual, any given cell could feasibly be hit by several storms in a year. Hence, to account for multiple strikes, we assume that damages can accumulate over a year, but set the index's annual value to have a maximum threshold of 1.

\section{Summary Statistics}

Table 1 provides summary statistics for the variables we use in our regression analysis for the 121,930 cells that took at least one nonzero value in nightlight intensity over the 1992-2013 period. As can be seen, some cells reach the maximum on the normalized scale of nightlights, but the average value is around 4. However, the standard deviation of about 8 indicates that there is substantial variation in this regard in our dataset. In terms of the typhoon destruction index $f$ there were a total of 59 storms over this sample period that produced nonzero values. Looking at its actual summary values, one finds that when a storm is damaging, it causes on average about $2 \%$ damage, while the highest observed damage in any cell over our sample period was close to $30 \%$. As with nightlights, the standard deviation of the damage index indicates that there is substantial variation in the index once a storm is damaging.

Table 1: Summary Statistics

\begin{tabular}{lcccc}
\hline Variable & Mean & Standard Deviation & Minimum & Maximum \\
\hline Nightlights & 3.996536 & 8.391635 & 0 & 63 \\
$f \neq 0$ & 0.0224685 & 0.0399104 & $4.42 \mathrm{e}-21$ & .2967033 \\
\hline
\end{tabular}

Source: Author's own, using nightlight intensity data from Defense Meteorological Satellite Program. 1992-2013. Version 4 DMSP-OLS Nighttime Lights Time Series. National Centers for Environmental Information, National Oceanic and Atmospheric Administration, United States Department of Commerce. https://ngdc.noaa.gov/eog/dmsp/downloadV4composites.htm. 


\section{ECONOMETRIC ANALYSIS}

\section{A. Regression Framework}

Our benchmark specification to investigate the impact of typhoon strikes on cell nightlight intensity is given by:

$$
N L_{i t}=\alpha+\sum_{l=0}^{L} \beta_{f_{t-l}} f_{i t-l}+\pi_{t}+\mu_{i}+\epsilon_{i t}
$$

where $N L$ is nightlight intensity of cell $i$ at time $t, f$ is our damage index, potentially including its lags (I), $\mu_{i}$ is cell specific time invariant effects, and $\epsilon$ is the error term. Time dummies $\pi_{t}$ are included to account for time-varying effects common to all plants. We take account of time-invariant cell-specific unobservables $\mu_{i}$ by using a fixed effects estimator. In order to allow for serial and spatial correlation, we calculate Driscoll and Kraay (1998) standard errors. Arguably our coefficient of interest, namely the effect of typhoon damage, $\beta_{f l}$, is unbiased from an economic decision-making perspective. More specifically, after controlling for fixed effects, any shocks in $f$ will simply be random realizations drawn from the typhoon distribution. Thus, local economic agents may make location and other decisions, taking into consideration the local distribution of typhoon damage, but the actual event will be unanticipated after controlling for cell fixed effects.

\section{B. Econometric Results}

We first estimate specification 4 only with contemporaneous values of $f$, the results of which are shown in the first column of Table 2. Accordingly, typhoon destruction has a negative and significant impact on nightlight intensity. We subsequently systematically include lagged values of $f$ into equation 4 , but these all proved to be insignificant, as can be seen from columns 2-5 of Table 2.

Table 2: Regression Results

\begin{tabular}{|c|c|c|c|c|c|c|}
\hline & (1) & (2) & (3) & (4) & (5) & (6) \\
\hline$f_{t}$ & $\begin{array}{r}-2.669^{*} \\
(1.102)\end{array}$ & $\begin{array}{c}-3.037^{*} \\
(1.244)\end{array}$ & $\begin{array}{l}-3.016^{*} \\
(1.249)\end{array}$ & $\begin{array}{c}-3.003^{*} \\
(1.247)\end{array}$ & $\begin{array}{l}-3.113^{*} \\
(1.239)\end{array}$ & \\
\hline$f_{t-1}$ & & $\begin{array}{r}3.193 \\
(2.391)\end{array}$ & $\begin{array}{r}3.115 \\
(2.513)\end{array}$ & $\begin{array}{r}3.139 \\
(2.494)\end{array}$ & $\begin{array}{r}3.064 \\
(2.446)\end{array}$ & \\
\hline$f_{t-2}$ & & & $\begin{array}{r}0.583 \\
(1.732)\end{array}$ & $\begin{array}{r}0.594 \\
(1.751)\end{array}$ & $\begin{array}{r}0.508 \\
(1.810)\end{array}$ & \\
\hline$f_{t-3}$ & & & $\begin{array}{r}-0.0679 \\
(1.048)\end{array}$ & $\begin{array}{r}-0.0816 \\
(1.032)\end{array}$ & $\begin{array}{r}-0.0845 \\
(1.041)\end{array}$ & \\
\hline$f_{t-4}$ & & & & $\begin{array}{r}-0.337 \\
(0.741)\end{array}$ & $\begin{array}{r}-0.336 \\
(0.734)\end{array}$ & \\
\hline$f_{t-5}$ & & & & & $\begin{array}{r}1.203 \\
(0.825)\end{array}$ & \\
\hline$f_{t+1}$ & & & & & & $\begin{array}{r}3.846 \\
(1.951) \\
\end{array}$ \\
\hline Observations & $2,682,460$ & $2,682,460$ & $2,682,460$ & $2,682,460$ & $2,682,460$ & $2,682,460$ \\
\hline Number of groups & 121,930 & 121,930 & 121,930 & 121,930 & 121,930 & 121,930 \\
\hline \multicolumn{7}{|c|}{$\begin{array}{l}\text { Notes: Standard errors allowing for 2-year serial correlation in parentheses. }{ }^{* *} \text { and * indicate } 1 \% \text { and } 5 \% \text { significance levels, respectively } \\
\text { All specifications include year dummies. All models are estimated using a panel fixed effects estimator. } \\
\text { Source: Author's calculations based on data from Knapp, Kenneth R., Michael C. Kruk, David H. Levinson, Howard J. Diamond, and, } \\
\text { Charles J. Neumann. 2010. "The International Best Track Archive for Climate Stewardship (IBTrACS) Unifying Tropical Cyclone Data." } \\
\text { Bulletin of the American Meteorological Society } 91 \text { (3): } 363-76 \text { and wind field model; and Driscoll, John C. and Aart C. Kraay. } 1998 . \\
\text { "Consistent Covariance Matrix Estimation with Spatially Dependent Panel Data." Review of Economics and Statistics } 80 \text { (4): 549-60. }\end{array}$} \\
\hline
\end{tabular}


As a placebo test, we also included $f$ at $t+1$ in 4 , i.e., a year prior to the actual storm occurrence. The estimated, shown in the last column of Table 2, reassuringly, is insignificant. We also implemented a Fisher type randomization test, where we randomly reshuffled years in our panel data, breaking the temporal link between damages and nightlight intensity. This allows us to compute the probability of observing our significant estimates compared to randomly assigning years. A histogram of the estimated $t$ statistics for $f_{t}$ is shown in Figure 8. As can be seen, compared to the distribution, the $t$ statistics under the randomization, the actual value, shown by the red vertical line, is unlikely to be random. As a matter of fact, the $t$ statistic for actual estimate on the contemporaneous value of the typhoon damage index is in the 0.01 portion of the tail.

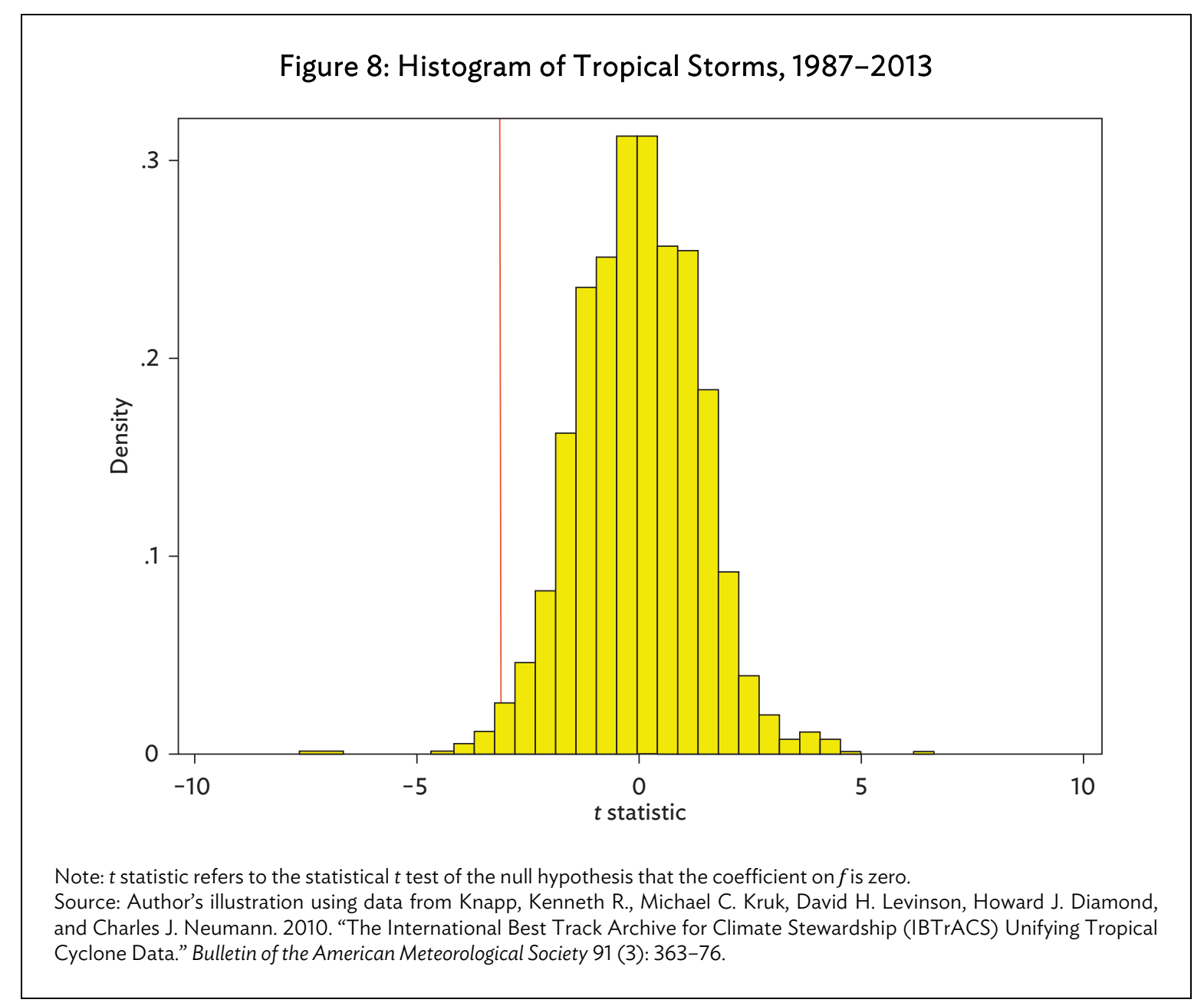

To put our estimates into an economic context, we consider the effect of the average annual damage incurred from a damaging typhoon, i.e., 2.24\%. Our estimated coefficient implies that this will cause about $3.113 * 0.022 / 4=0.017$, i.e., about a $1.7 \%$ reduction in nightlight intensity. If we take the largest observed storm damage $(f=0.297)$, then this impact will be $3.1139 * 0.297 / 4=0.23$, i.e., a $23 \%$ reduction in local economic activity as measured by nightlight intensity. We can also calculate the total reduction in economic activity due to typhoons over the period 1992-2013 by using our estimated coefficient, multiplying it by the observed values of $f$ at the cell level, summing implied nightlight reduction nationally, and comparing it to total national nightlight intensity. Doing so suggests an average annual loss of a little less than a half percent (0.48\%), with the largest loss (1.96\%) occurring in 2006. 


\section{RISK ANALYSIS}

\section{A. Extreme Value Analysis}

It is common practice to model the probabilities of relatively rare occurrences using extreme value theory, see for instance Jagger and Elsner (2006) for hurricane wind modeling. One result of Extreme Value Theory is that there are three possible limit distributions for maxima of independent random variables: the Fr' echet, the Gumbel and the Weibull, which can all be cast within the Generalized Extreme Value family. Depending on the value of their exponent, they have finite tails, exponential or power tails. A standard approach in modeling extremes is the Peaks Over Threshold (POT) model, based on the Pickands Balkema de Haan theorem, which states that for a large class of distributions, exceedances over a high threshold $m$ are well approximated by a Generalized Pareto Distribution (GPD), which is characterized by a scale parameter $\sigma$ and by a shape parameter $\zeta$, whose value corresponds to the tail parameter as the Generalized Extreme Value. We thus consider that for each region $i$, the distribution of typhoon impacts, $L_{i}$, can be approximated as follows:

$$
P\left(L_{i} \leq x\right)=\left\{\begin{array}{lr}
\left(1-F_{i, n}\left(m_{i}\right)\right)\left(1-\left(1+\zeta \frac{x-m_{i}}{\sigma_{i}}\right)_{z_{+}}^{-1 / \zeta_{i}}\right)+F_{i, n}\left(m_{i}\right) ; & \text { for } x \geq m_{i} \\
F_{i, n}\left(m_{i}\right) ; & \text { for } x<m_{i}
\end{array}\right.
$$

where $z_{+}=\max (0, z)$, and $F_{n}(x)=\frac{1}{n} \sum_{j} 1_{\left\{L_{i j} \leq x\right\}}$ is the empirical distribution of an indicator function when $x$ is greater than or equal to $L_{i j}$, based on the sample $\left(L_{i 1}, \ldots, L_{i n}\right)$. A negative value of the shape parameter $\zeta_{i}$ implies that the distribution follows a short-tailed Pareto distribution. In contrast, when $\zeta_{i}=0$, the distribution has a thin tail with exponential decay and follows an exponential distribution. Finally, when $\zeta_{i}>0$, the distribution has a fat tail, with a power decay, and can be considered an ordinary Pareto distribution.

\section{B. Threshold Selection}

An important task in modeling threshold excesses is the choice of the threshold $m$. A standard approach is to examine mean residual (MRL) plots. More specifically, the basic idea is that if the generalized Pareto distribution is valid for excesses of the threshold $m$ then it should be equally valid for all thresholds above $m$. As noted by Coles (2001), this means that the mean of the excesses $E(L-$ $m \mid L>m$ ) should change linearly with increases in $m$. One can check this by examining the locus of points:

$$
\left\{\left(m, \frac{1}{n_{m}} \sum_{i=1}^{n_{m}}\left(L_{(i)}-m\right)\right): m<L_{\max }\right\}
$$

where $L_{(i)}, \ldots, L_{\left(n^{m}\right)}$ consist of the $n_{m}$ observations that exceed $m$ and $L_{\max }$ is the largest of the $L_{i}$. Graphing the locus of points from equation (6) provides the MRL.

\section{Results}

To generate a distribution of losses, we took all tropical storms from the IBTrACS dataset from 1950 to 2013 , interpolated these to hourly values and then, using the nonzero cell grids of 2013, calculated the implied damage under each storm and each cell using equations (1), (2), and (3). We then multiplied 
the value of the nightlight intensity of the cell with the estimated coefficient on $f_{t}$ from Table 2 to calculate storm by cell losses. Summing the implied losses in nightlight intensity for each cell nationally or by region, by storm, provided a distribution of losses from which we can estimate an extreme value distribution. Importantly, one may want to note that we are thus implicitly assuming that the distribution of losses over the period 1950-2013 is stationary.

Starting first with the nationally implied loss distribution, we chart the implied MRL plot in Figure 9. Accordingly, a threshold of 5,000 seems reasonable, in that the MRL plot is roughly linear thereafter, but one still has enough observations to estimate a POT model.

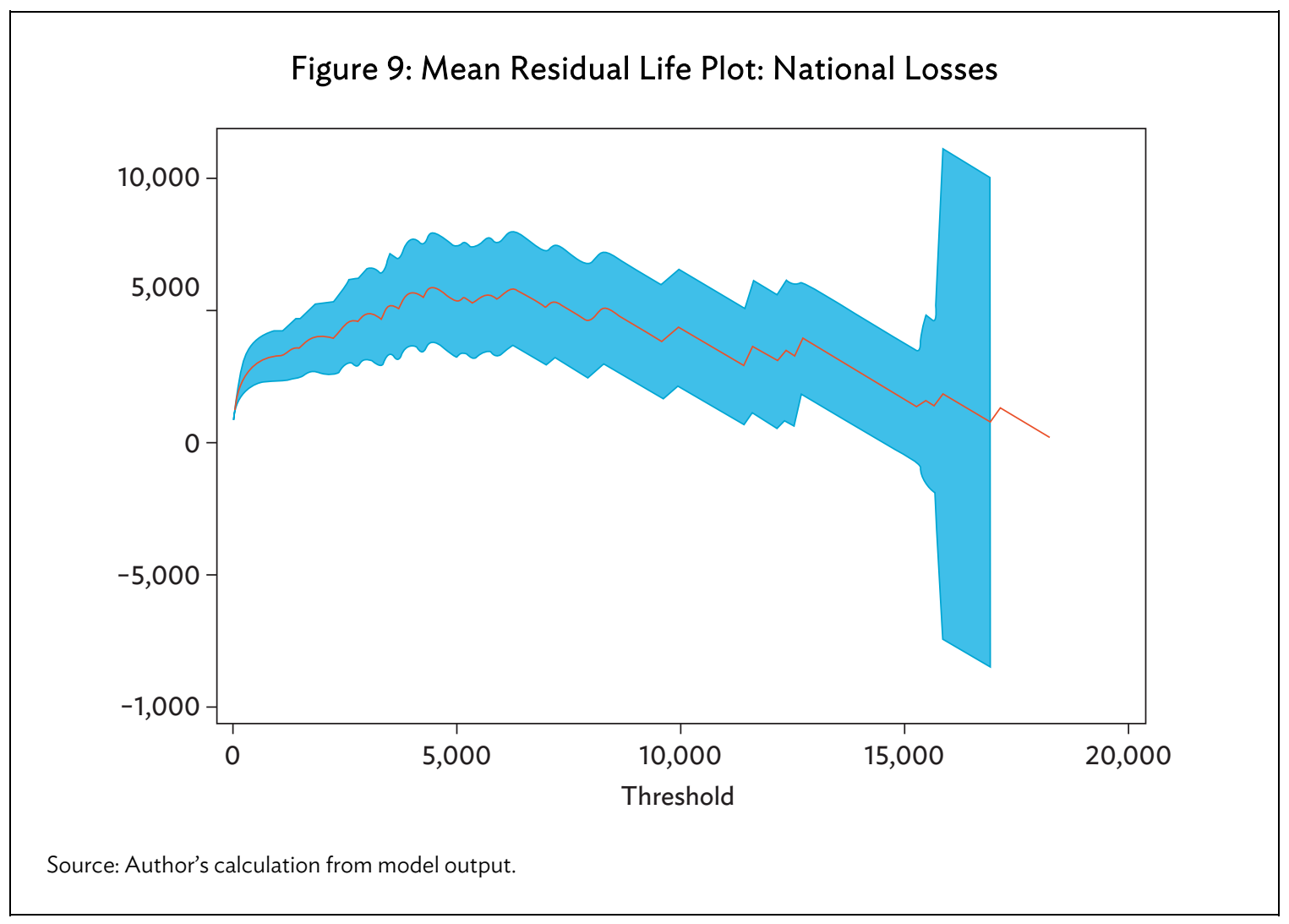

We next estimated a GPD model with the threshold of 5,000 using maximum likelihood methods. This produced an estimate of the scale parameter $\sigma$ of 9,565.98 and the shape parameter $\zeta$ of -0.68 , both statistically significant at the $5 \%$ level. Thus, the estimated GDP has a short-tailed Pareto distribution. To assess the empirical fit of our estimated model, we plot the empirical quantiles versus model quantiles in Figure 10, also known as the qq plot. As can be seen, these follow relatively closely the diagonal line and thus the empirical fit is reasonably satisfactory. 


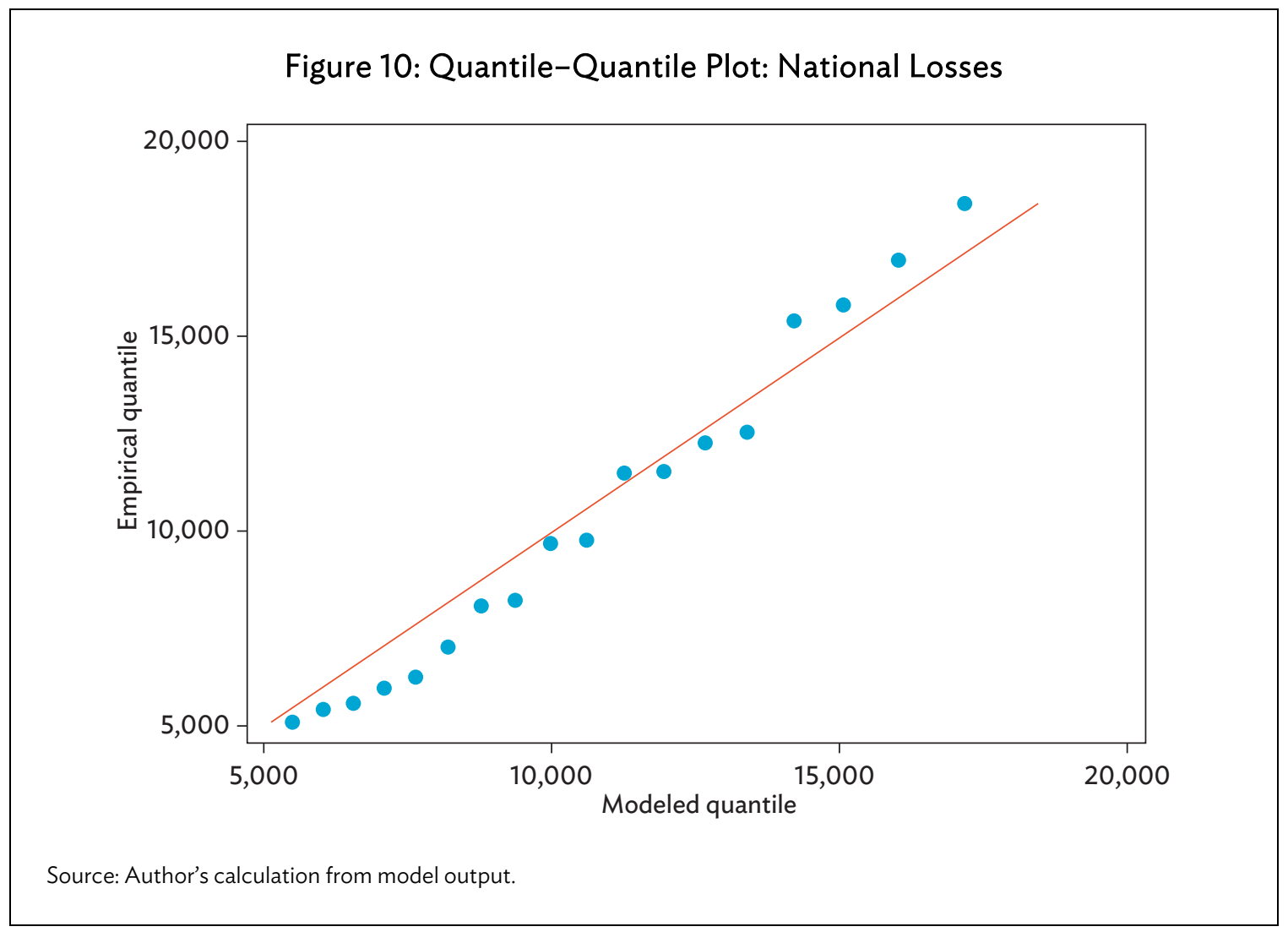

We can now use our estimated POT model to calculate the expected losses of corresponding return periods. More specifically, a given level of losses $L_{s}$, with return period $s$, above threshold $m$ is equal to:

$$
L_{s}=m+\frac{\sigma}{\zeta}\left[\left(S \zeta_{m}\right)^{\zeta}-1\right]
$$

where $\zeta_{m}=P\{L>m\}$. We plot the losses associated with return periods from 5 to 50 years, calculated as a percent of total 2013 nightlight intensity in the Philippines, along with 95\% confidence bands, in Figure 11.

Looking at the estimates more precisely, one finds that a 5-year return period storm will produce losses of about $1 \%$ of national economic activity. This rises as one considers rarer and rarer events. For example, 10-year, 20-year, and 50-year return period losses result in $1.6 \%$, 2\%, and $2.4 \%$ reduction, respectively, of total national economic activity in the year of the storm as estimated by nightlight intensity. One may want to note that the rise in losses with increasing return periods is relatively gradual, as is common with short-tailed distributions, which we have here. 
Next we examined the implied distribution of total losses at the regional level, as shown in Figure 12. To this end, we, as with the national series, established region-specific thresholds by examining the corresponding MRL plots, and then estimated the region-specific GPD distributions using these. ${ }^{5}$ This allowed us to then calculate $n$-year return period losses for each region.

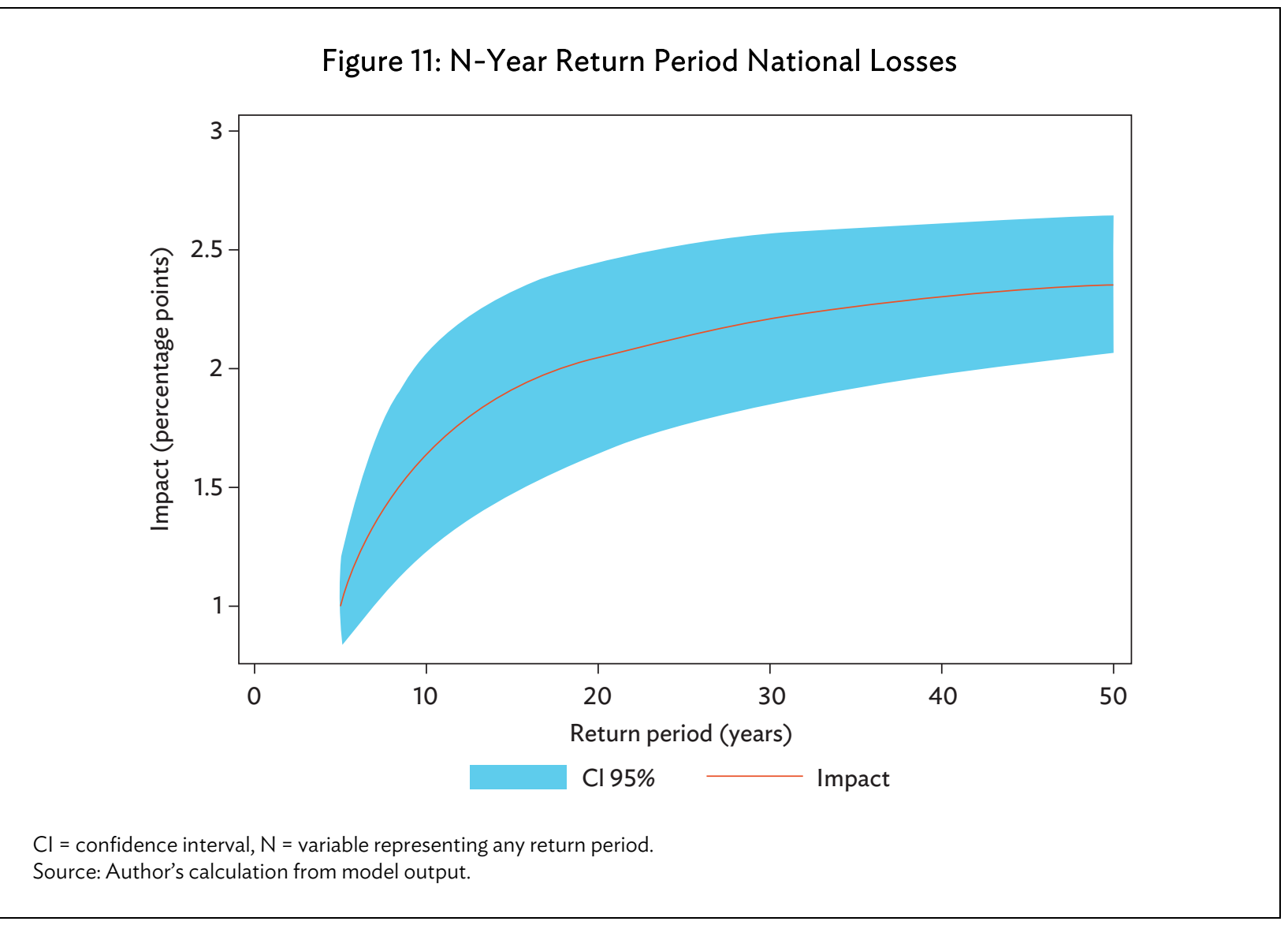

We report these for 5-, 10-, 20-, and 50-year return periods for reach region in Table 3. Accordingly, the expected losses differ considerably regionally. More specifically, highest losses are expected in Region VIII, followed closely by Region II. For instance, for Region VIII, 5-, 10-, 20-, and 50 -year return period damaging typhoons correspond to 7.58, 14.5, 17.96, and 20.04 percentage losses in economic activity, respectively. In contrast, losses are fairly low in the National Capital Region, Region IX, or Region XII. For these three areas, even 20-year return period storms are not likely to cause more than $1 \%$ reduction in contemporary economic activity.

5 One should note that for some regions, there were difficulties in reaching convergence in the maximum likelihood estimation given the small number of observations above the chosen threshold. For these we took the estimates achieved after 1,600 iterations. It is for this reason that we do not report confidence intervals, since for some regions, these could not be calculated due to the lack of convergence. 


\section{Figure 12: Regions of the Philippines}

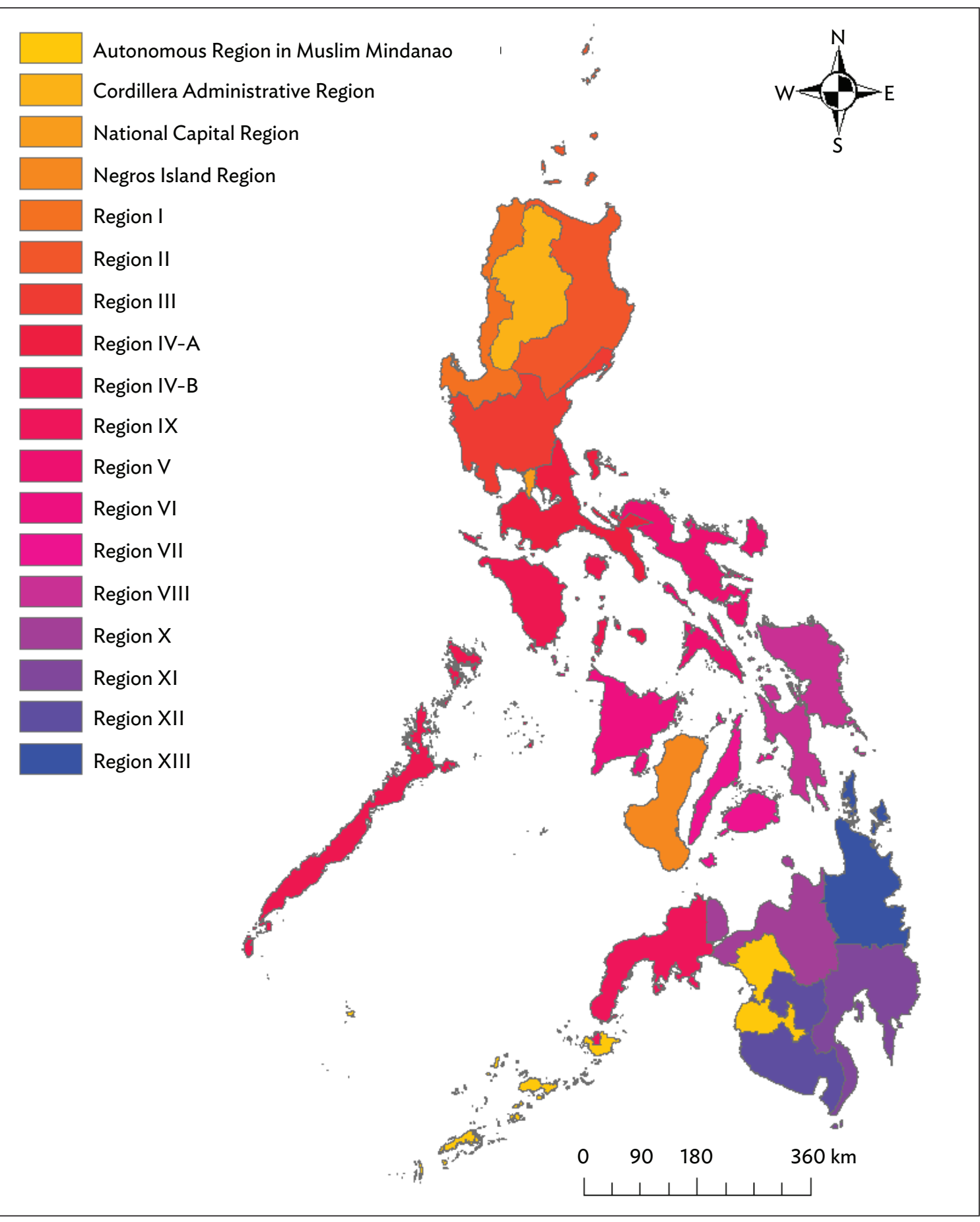

$\mathrm{E}=$ east, $\mathrm{km}=$ kilometer, $\mathrm{N}=$ north, $\mathrm{S}=$ south, $\mathrm{W}=$ west.

Source: GADM. 2018. "Database of Global Administrative Areas.” https://gadm.org/. 


\section{Table 3: Impact Return Periods by Region}

$(\%)$

\begin{tabular}{lcccc}
\hline Region & 5 Years & 10 Years & 20 Years & 50 Years \\
\hline Autonomous Region in Muslim Mindanao & 1.63 & 1.69 & 1.72 & 1.74 \\
Cordillera Administrative Region & 3.17 & 8.45 & 10.8 & 12.03 \\
National Capital Region & 0.50 & 0.67 & 0.76 & 0.81 \\
Negros Island Region & 4.92 & 5.68 & 5.81 & 5.83 \\
Region I & 3.67 & 5.77 & 6.81 & 7.43 \\
Region II & 1.60 & 13.13 & 17.85 & 20.12 \\
Region III & 2.19 & 3.07 & 3.73 & 4.35 \\
Region IV-A & 1.46 & 2.07 & 2.69 & 3.54 \\
Region IV-B & 3.91 & 5.49 & 6.25 & 6.68 \\
Region IX & .09 & 0.09 & 0.09 & 0.09 \\
Region V & 9.37 & 11.76 & 14.74 & 19.85 \\
Region VI & 3.25 & 4.65 & 5.32 & 5.71 \\
Region VII & 1.14 & 5.05 & 6.48 & 7.09 \\
Region VIII & 7.58 & 14.50 & 17.96 & 20.04 \\
Region X & 4.67 & 8.94 & 11.08 & 12.36 \\
Region XI & 1.21 & 1.30 & 1.34 & 1.37 \\
Region XII & 0.75 & 0.81 & 0.84 & 0.85 \\
Region XIII & 5.32 & 8.34 & 9.84 & 10.75 \\
\hline Note Data & & & \\
\hline
\end{tabular}

Note: Data are generated using region-specific thresholds and Generalized Pareto Distribution models.

Source: Author's calculation.

\section{CONCLUSIONS}

In this paper, we quantified the economic impact of typhoons in the Philippines. To this end, we used satellite-derived measures of nightlight intensity as measures of local economic activity and combined these with constructed damages based on storm tracks, a wind field model, and a stylized damage function. Econometric analysis of our constructed panel dataset over 21 years showed that the impact can be substantial for the most damaging storms, but does not last beyond a year. Using a set of historical storm tracks observed over the last 60 years, we then constructed risk profiles. These suggested that relatively frequent storms, i.e., those with a return period of at least 5 years are likely to cause about a $1 \%$ short-term reduction in economic activity, while rarer storms, such as those with return periods of at least 20 years are likely to induce a reduction of at least $2 \%$. These predictions differ starkly across regions in the Philippines.

While our analysis provides arguably a good starting point with which to quantitatively assess the economic impact of typhoons in the Philippines, there are a number of weaknesses that could be addressed with future research. For one, nightlights are likely to directly best capture a very specific aspect of economic activity, namely those associated with using lighting at night, such as services or manufacturing. In contrast, while the use of electricity is likely to have some positive relationship with 
other forms of local production, such as agriculture, it is not clear how much this is the case, and thus how much the results here are underestimating the total local and national impact. Further research in this regard could prove a fruitful input into the analysis. Additionally, the risk analysis undertaken here suffers from three weaknesses that could be addressed in the future.

Firstly, the risk analysis undertaken here rests on the important assumptions that past historical storms are reflective of current climate and that this climate can be used to predict typhoon activity in the (near) future. Including predictions under different climate change scenarios could additionally provide a further sense of the range of possible outcomes for the longer-term future. Secondly, one may also want to take into account the likely growth of vulnerability in affected coastal areas through population expansion and environmental degradation in the predictions. The third weakness concerns the role of typhoon warnings. Clearly, if typhoon warnings are issued in a timely manner, the reactions to that could reduce the negative effect of the storms, which is likely to have become more important in recent years when warnings are issued by the Philippines Atmospheric, Geophysical, and Astronomical Services Administration. Future research with more recent nightlight intensity data could explicitly try to quantify the role of warnings in dampening the effect of typhoons on local economic activity. 


\section{REFERENCES}

Ahlerup, Pelle. 2013. "Are Natural Disasters Good for Economic Growth?" Technical Report. University of Gothenburg, Department of Economics.

Anttila-Hughes, Jesse, and Solomon Hsiang. 2013. "Destruction, Disinvestment, and Death: Economic and Human Losses Following Environmental Disaster." Available at SSRN: https://ssrn.com/abstract=2220501 or http://dx.doi.org/10.2139/ssrn.2220501.

Bertinelli, Luisito, and Eric Strobl. 2013. "Quantifying the Local Economic Growth Impact of Hurricane Strikes: An Analysis from Outer Space for the Caribbean." Journal of Applied Meteorology and Climatology 52 (8): 1688-97.

Blanc, Elodie, and Eric Strobl. 2016. "Assessing the Impact of Typhoons on Rice Production in the Philippines." Journal of Applied Meteorology and Climatology 55 (4): 993-1007.

Boose, Emery R., Mayra I. Serrano, and David R. Foster. 2004. "Landscape and Regional Impacts of Hurricanes in Puerto Rico.” Ecological Monographs 74 (2): 335-52.

Coles, Stuart. 2001. An Introduction to Statistical Modeling of Extreme Values (Volume 208). London: Springer-Verlag.

Craioveanu, Mihaela, and Dek Terrell. 2016. "The Impact of Storms on Firm Survival: A Bayesian Spatial Econometric Model for Firm Survival." In Spatial Econometrics: Qualitative and Limited Dependent Variables, 81-118. Emerald Group Publishing Limited.

Crespo Cuaresma, Jesus, Jaroslava Hlouskova, and Michael Obersteiner. 2008. "Natural Disasters as Creative Destruction? Evidence from Developing Countries." Economic Inquiry 46 (2): 214-26.

Defense Meteorological Satellite Program. 1992-2013. Version 4 DMSP-OLS Nighttime Lights Time Series. National Centers for Environmental Information, National Oceanic and Atmospheric Administration, United States Department of Commerce. https://ngdc.noaa.gov/eog/dmsp/ downloadV4composites.htm.

Driscoll, John C., and Aart C. Kraay. 1998. "Consistent Covariance Matrix Estimation with Spatially Dependent Panel Data." Review of Economics and Statistics 80 (4): 549-60.

Elliott, Robert J.R., Eric Strobl, and Puyang Sun. 2015. "The Local Impact of Typhoons on Economic Activity in China: A View from Outer Space." Journal of Urban Economics 88: 50-66.

Elvidge, Christopher, Kimberly Baugh, Vinita Hobson, Eric Kihn, Herbert Kroehl, Ethan Davis, and David Cocero. 1997. "Satellite Inventory of Human Settlements Using Nocturnal Radiation Emissions: A Contribution for the Global Toolchest.” Global Change Biology 3 (5): 387-95.

Emanuel, Kerry A. 2011. "Global Warming Effects on US Hurricane Damage." Weather, Climate, and Society 3 (4): 261-68. 
2013. "Downscaling CMIP5 Climate Models Shows Increased Tropical Cyclone Activity Over the 21st Century." Proceedings of the National Academy of Sciences 110 (30): 12219-24.

GADM. 2018. “Database of Global Administrative Areas.” GADM. https://gadm.org/.

Groen, Jeffrey A., Mark J. Kutzbach, and Anne E. Polivka. 2017. "Storms and Jobs: The Effect of Hurricanes on Individuals' Employment and Earnings Over the Long Term.” BLS Working Paper No. 499.

Harari, Mariaflavia, and Eliana La Ferrara. 2013. "Conflict, Climate and Cells: A Disaggregated Analysis." CEPR Discussion Paper No. DP9277.

Hodler, Roland, and Paul Raschky. 2014. "Regional Favoritism." The Quarterly Journal of Economics 129 (2): 995-1033. http://qje.oxfordjournals.org/content/129/2/995.abstract.

Holden, William N., and Shawn J. Marshall. 2018. "Climate Change and Typhoons in the Philippines: Extreme Weather Events in the Anthropocene." In Integrating Disaster Science and Management, 407-21. Elsevier.

Holland, Greg J. 1980. "An Analytic Model of the Wind and Pressure Profiles in Hurricanes." Monthly Weather Review 108 (8): 1212-18.

—. 2008. "A Revised Hurricane Pressure-Wind Model." Monthly Weather Review 136 (9): $3432-45$.

Jagger, Thomas H., and James B. Elsner. 2006. Climatology Models for Extreme Hurricane Winds Near the United States." Journal of Climate 19 (13): 3220-36.

Knapp, Kenneth R., Michael C. Kruk, David H. Levinson, Howard J. Diamond, and Charles J. Neumann. 2010. "The International Best Track Archive for Climate Stewardship (IBTrACS) Unifying Tropical Cyclone Data." Bulletin of the American Meteorological Society 91 (3): 363-76.

Knutson, Thomas R., John L. McBride, Johnny Chan, Kerry Emanuel, Greg Holland, Chris Landsea, Isaac Held, James P. Kossin, A.K. Srivastava, and Masato Sugi. 2010. "Tropical Cyclones and Climate Change." Nature Geoscience 3: 157-63.

Leiter, Andrea M., Harald Oberhofer, and Paul A. Raschky. 2009. "Creative Disasters? Flooding Effects on Capital, Labour and Productivity Within European Firms." Environmental and Resource Economics 43 (3): 333-50.

Loayza, Norman V., Eduardo Olaberria, Jamele Rigolini, and Luc Christiaensen. 2012. "Natural Disasters and Growth: Going beyond the Averages." World Development 40 (7): 1317-36.

Michalopoulos, Stelios, and Elias Papaioannou. 2014. "National Institutions and Subnational Development in Africa." The Quarterly Journal of Economics 129 (1): 151-213.

Mohan, Preeya, and Eric Strobl. 2017. "The Short-Term Economic Impact of Tropical Cyclone Pam: An Analysis Using VIIRS Nightlight Satellite Imagery.” International Journal of Remote Sensing 38 (21): 5992-6006. 
Noy, Ilan, and William duPont IV. 2016. "The Long-Term Consequences of Natural Disasters-A Summary of the Literature. Victoria University of Wellington School of Economics and Finance Working Paper No. 02/2016.

Paulsen, Becca M., and John L. Schroeder. 2005. "An Examination of Tropical and Extratropical Gust Factors and the Associated Wind Speed Histograms." Journal of Applied Meteorology 44 (2): 270-80.

Paxson, Christina, and Cecilia Elena Rouse. 2008. "Returning to New Orleans after Hurricane Katrina." American Economic Review 98 (2): 38-42.

Philippines Statistics Authority. 2015. “Revised Q1 2015 Lower at 5.0 Percent.” 26 August. Manila. https://ngdc.noaa.gov/eog/dmsp/downloadV4composites.html.

Strobl, Eric. 2011. "The Economic Growth Impact of Hurricanes: Evidence from US Coastal Counties." Review of Economics and Statistics 93 (2): 575-89.

_ 2012. "The Economic Growth Impact of Natural Disasters in Developing Countries: Evidence from Hurricane Strikes in the Central American and Caribbean Regions." Journal of Development Economics 97 (1): 130-141.

Vickery, Peter J., Forrest J. Masters, Mark D. Powell, and Dhiraj Wadhera. 2009. "Hurricane Hazard Modeling: The Past, Present, and Future." Journal of Wind Engineering and Industrial Aerodynamics 97 (7-8): 392-405.

Xiao, Yu Feng, Yongjian Xiao, and Zhongdong Duan. 2009. "The Typhoon Wind Hazard Analysis in Hong Kong of China with the New Formula for Holland B Parameter and the CE Wind Field Model." Prepared for the Seventh Asia-Pacific Conference on Wind Engineering. Taipei,China. 8-12 November. 


\section{The Impact of Typhoons on Economic Activity in the Philippines: Evidence from Nightlight Intensity}

Typhoons are shown to have a significant negative, but short-lived impact on local economic activity in the Philippines, as proxied by the intensity of light usage at night measured from satellites. Using this proxy, an analysis of the historical distribution of typhoons was conducted to predict future impacts. A key finding was that frequent, low-damaging typhoons are likely to reduce local economic activity by around $1 \%$, while rarer, but more intense typhoons, will cause a reduction of up to nearly $3 \%$. Another finding was that the severity of the impacts will differ widely between regions in the Philippines.

\section{About the Asian Development Bank}

ADB is committed to achieving a prosperous, inclusive, resilient, and sustainable Asia and the Pacific, while sustaining its efforts to eradicate extreme poverty. Established in 1966, it is owned by 68 members -49 from the region. Its main instruments for helping its developing member countries are policy dialogue, loans, equity investments, guarantees, grants, and technical assistance. 